\title{
Safety Ontology Modeling and Verification on MIS of Ship-Building and Repairing Enterprise
}

\author{
Yumei $\mathrm{Wu}^{1}$, Zhen $\mathrm{Li}^{2 *}$, LanJie $\mathrm{Zhao}^{2}$, Zhengwei $\mathrm{Yu}^{1}$, and Hong Miao ${ }^{3}$ \\ ${ }^{1}$ School of Reliability and Systems Engineering, Beihang University \\ Beijing,100191, China \\ [e-mail: wuyumei@buaa.edu.cn] \\ ${ }^{2}$ School of Electronics and Information, Jiangsu University of Science and Technology \\ Zhenjiang, JiangSu Province, 212003, China \\ [e-mail: justlz@just.edu.cn,664198673@qq.com] \\ ${ }^{3}$ School of Economics and Management, Jiangsu University of Science and Technology \\ Zhenjiang, JiangSu Province,212003, China \\ [e-mail: buaayuzhengwei@163.com] \\ *Corresponding author: Zhen Li
}

Received July 27, 2020; revised March 7, 2021; March 28, 2021;

published April 30, 2021

\begin{abstract}
Shipbuilding and repairing enterprise has the characteristics of many hazards and accidents. Therefore, the safety management ability of shipbuilding and repairing MIS (management information system) must be effectively guaranteed. The verification on safety management is the necessary measure to ensure and improve the safety management ability of MIS. Safety verification can not only increase the safety of MIS, but also make early warning of potential risks in management to avoid the accidents. Based on the authoritative standards in the field of safety in shipbuilding and repairing enterprise, this paper applied modeling and verification method based on ontology to safety verification of MIS, extracted the concepts and associations from related safety standards to construct axiom set to support safety verification on MIS of shipbuilding and repairing enterprise. Then, this paper developed the corresponding safety ontology modeling and verification tool-SOMVT. By the application and comparison of two examples, this paper effectively verified the safety of MIS to prove the modeling method and the SOMVT can improve the safety of MIS in a much more effective and stable way to traditional manual analysis.
\end{abstract}

Keywords: Management Information System, Safety, Ontology, Reliability Engineering

This research was supported by a research grant from the Research Collabration of Industry and University, JiangSu Province[BY2019014,Safety Modeling and Analysis Technology of Critical System] and Jiangsu University of Science and Technology, Reliability and System Engineering Open Group (JRSOG) Open Fund[2020001, Safety Modeling and Analysis Technology of MIS]. 


\section{Introduction}

In recent years, the production process of ship building and repair enterprises are supported by more and more information technology [1].The MIS significantly improves the operation efficiency and quality of the enterprise [2]. However, the MIS still lacks strong support to the safety production management at present. By verifying the safety ability of MIS, finding and solving the existing safety problems can effectively improve the safety management ability of the enterprise. At the same time, there have exsited standards and manuals related to safety management of enterprise, which provides a natural and authoritative basis for building and verifying the safety management ability of MIS from those standard, and also lays a foundation for its ontology model [3-4]. This paper aimed at the safety ability of MIS in shipping industry. By improvement on the MIS using ontology method and developed tool, we can increase the safety of process and management of shipping industry. Therefor, the safety of the information system is an objective in this research paper and the safety in shipping industry is the final objective in practice.

\section{Related Work}

The safety ability of MIS is crucial to the enterprise, so researchers have paid close attention to the safety of enterprise information system. Relevant research mainly focuses on establishing relevant safety MIS on ISO27000 related standards, such as five stages information safety management system (5S2IS) proposed by Alan Gillies [5]. In theoretical research, Du Jinsong believes that the implementation, operation, monitoring, review, maintenance and improvement processes should be included in the safety MIS model [6]. In practical research, Liu Jingjing improved the safety MIS of a company based on the international general standards and the "PDCA" process methodology, and formulated an effective safety MIS strategy [7].

At present, there are two main directions in the research of safety MIS [8-11]:

(1) Find and eliminate systematic safety problems from the source, to change the level of information safety from a fluctuating state to a stable and reliable state.

(2) Combine information safety management with the enterprise's business system, through strengthening integration, improve the enterprise's production and operation process, and enhance competition and the ability to resist risks as a whole.

This paper deeply analyzed the selected standards and manuals in the field of information system safety. Starting from those standards and manuals, we used the ontology modeling method to create the shared concepts and associations of ship building and repairing enterprise. This paper established the safety ontology model of MIS of ship building and repairing enterprise, analyzed the safety problems existing in the MIS based on this model, completed the verification of its safety management ability, gave the detailed result information and implemented the safety optimization of MIS.

\section{Basic Concepts}

\subsection{Definition of Ontology}

In terms of concept definition, the most popular definition of ontology is "ontology is the specification of conceptualization" proposed by Gruber in 1993[12]. In terms of formal definition, there are many forms of ontology from two tuples to six tuples: 
(1) $C=\{D, W\}$, where $\mathrm{D}$ represents a domain, $\mathrm{W}$ represnets all possible states in the domain.

(2) $C=\{D, W, R\}$, which comes from the definiton of two tuples, $\mathrm{R}$ is the set of relations based on $C=\{D, W\}$.

(3) Onto $\log y=\{D, C o n, A t t, A s s\}$, where $\mathrm{D}$ is the domain of ontology applied which is a single or multiple domains; Con is the set of concepts in D; Att is attribution set based on Con, where Ass : Con $\times$ Con $\rightarrow\{0,1\} \wedge(d \notin D, t \in D, A s s(t, d)=0)$.

(4) Onto $\log y=\{C, R, H C$, rel, $A O\}$, where $\mathrm{C}$ is the set of concepts; $\mathrm{R}$ is the relation set of concepts; $\mathrm{HC}$ is the hierarchy of concepts; rel is thetuples function of relation between two concepts; $\mathrm{AO}$ is the axiom set.

(5) Onto $\log y=\left\{C, A^{C}, R, A^{R}, H, X\right\}$. where: $C$ Represents the relevant concept set of ontology in the domain; $A^{C}$ represents the attribute set based on each concept; $R$ represents the association set between concepts; $A^{R}$ represents the attribute set of each association; $H$ represents the hierarchical relationship based on the concept set, which has a parent-child relationship; $X$ represents an axiom set, in which each axiom represents a concept attribute, an association attribute and constraints among conceptual objects.

This paper took ontology as definiton in the six tuples which is more clear to help the research and tool development.

\subsection{Ontology Modeling Method}

In the research of ontology modeling methods, "seven steps" modeling method can not only reflect the characteristics of ontology, but also constantly modify and optimize the ontology model through applied modeling to achieve more complex ontology model, and the better reusability of ontology model [13].

Dr. Li Jing [14] evaluated the maturity of ontology method and made a conclusion that there is "seven steps" [13], METHONTOLOGY [15]> IDEF5 [16]> TOVE [17] > Skeletal Methodology [18] $>$ SENSUS [19]、KACTUS [20] sorted in the maturity.

Therefore, this paper selected "seven steps" method as ontology modeling method in this paper. The ontology modeling process of "seven steps" is shown in Fig. 1.

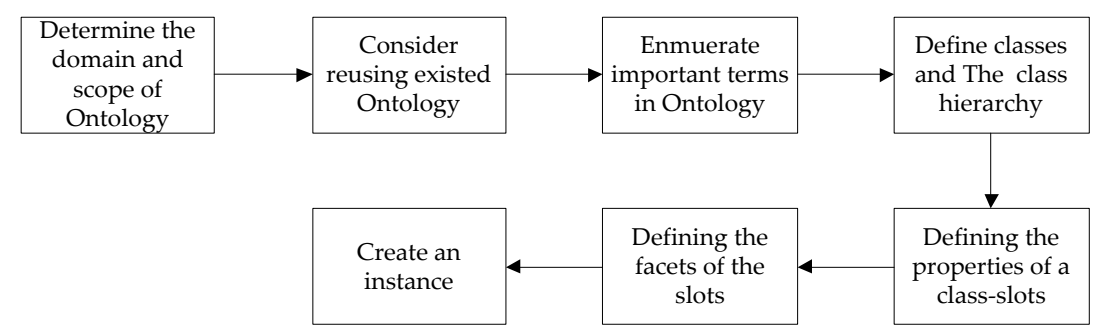

Fig. 1. "Seven step" modeling process

The seven steps are detailed describled as below:

\section{1) Determine the domain and scope of ontology}

The first step in "seven step" is to clarify the domain and scope which is needed to answer several questions:

(1) What is the domain that the ontology will cover?

(2) For what we are going to use the ontology?

(3) For what types of questions the information in the ontology should provide answers? 
(4) Who will use and maintain the ontology?

(5) What are the professional competency problems the ontology can answer?

\section{2) Consider reusing existed ontology}

If your system need interoperability with other applied platform which is based on specific ontolgy, the most effective solution is to reuse exsited ontology.

\section{3) Enumerate important terms in ontology}

It is useful to write down a list of all terms we would like either to make statements about or to explain to a user. What are the terms we would like to talk about? What properties do those terms have? What would we like to say about those terms?

Initially, it is important to get a comprehensive list of terms without worrying about overlap between concepts they represent, relations among the terms, or any properties that the concepts may have, or whether the concepts are classes or slots.

\section{4) Define the classes and the class hierarchy}

There are several possible approaches in developing a class hierarchy:

- A top-down development process starts with the definition of the most general concepts in the domain and subsequent specialization of the concepts.

- A bottom-up development process starts with the definition of the most specific classes, the leaves of the hierarchy, with subsequent grouping of these classes into more general concepts.

- A combination development process is a combination of the top-down and bottom-up approaches: We define the more salient concepts first and then generalize and specialize them appropriately. We might start with a few top-level concepts, and a few specific concepts. We can then relate them to a middle-level concept.

\section{5) Define the properties of classes-slots}

The classes alone will not provide enough information to answer the competency questions from Step 1. Once we have defined some of the classes, we must describe the internal structure of concepts. In general, there are several types of object properties that can become slots in an ontology:

- "intrinsic" properties such as the flavor of a wine;

- "extrinsic" properties such as a wine's name, and area it comes from;

- parts, if the object is structured; these can be both physical and abstract "parts" (e.g., the courses of a meal)

- relationships to other individuals

\section{6) Define the facets of the slots}

Slots can have different facets describing the value type, allowed values, the number of the values (cardinality), and other features of the values the slot can take. We now described several common facets.

\section{- Slot cardinality}

Slot cardinality defines how many values a slot can have. Some systems distinguish only between single cardinality (allowing at most one value) and multiple cardinality (allowing any number of values).

\section{- Slot-value type}


Here is a list of the more common value types:

$>$ String is the simplest value type that is used for slots such as name: the value is a simple string

Number (sometimes more specific value types of Float and Integer are used) describes slots with numeric values.

Boolean slots are simple yes-no flags.

Enumerated slots specify a list of specific allowed values for the slot.

Instance-type slots allow definition of relationships between individuals

- Domain and range of a slot

Allowed classes for slots of type Instance are often called a range of a slot. Some systems allow restricting the range of a slot when the slot is attached for a particular class.

\section{7) Create instances}

The last step is creating individual instances of classes in the hierarchy. Defining an individual instance of a class requires (1) choosing a class, (2) creating an individual instance of that class, and (3) filling in the slot values.

In the process of ontology model creation, the process in "seven steps" can be adjusted and optimized in practice. Such as the step five and step six are both edition of class and in tight relation, so those two steps can be merged.

\section{Modeling and Verification}

\subsection{Method and Process}

Based on the related safety standards and enterprise ontology, using seven step modeling method, this paper extracted concepts and associations to establish the ontology models. Then this paper used concepts and associations to describe the safety constraints on formal logic description (SHIQ) [21] in the standard to form axioms and generated a complete safety ontology of enterprise management for modeling and verification. The method and process are shown in Fig. 2.

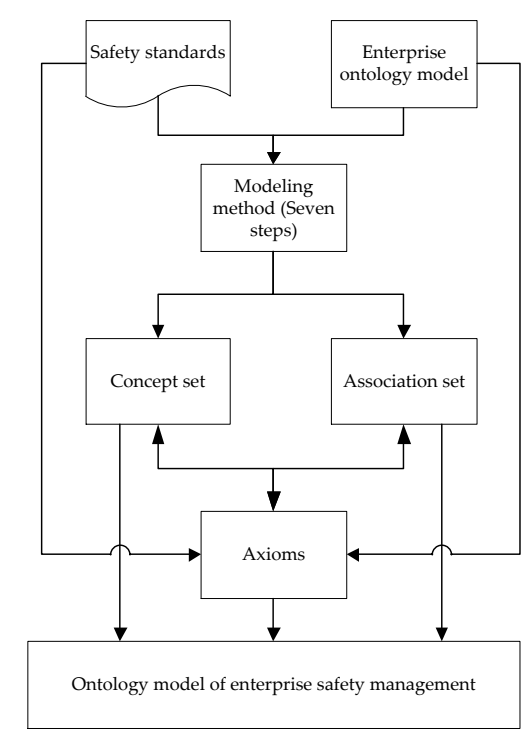

Fig. 2. Flow chart of model creation 


\subsection{Modeling}

\subsubsection{Standards Selected}

The core of ontology is explicit description of shared concepts, so the extraction of concepts must be widely recognized. This paper selected authoritative safety management standards as the research basis including ship building \& repair enterprises and related fields, then created the top-level ontology model. The selected standards are shown in Table 1.

Table 1. Selected enterprise safety management standards

\begin{tabular}{|l|l|l|l|}
\hline \multicolumn{1}{|c|}{ Standard No. } & \multicolumn{1}{|c|}{ Standard name } & Release mechanism & \multicolumn{1}{c|}{ Type } \\
\hline AQ/T 9006-2010 & $\begin{array}{l}\text { Basic norms for standardization of } \\
\text { enterprise safety management }\end{array}$ & $\begin{array}{l}\text { State Administration } \\
\text { of work safety }\end{array}$ & $\begin{array}{l}\text { General } \\
\text { standards }\end{array}$ \\
\hline GB 18218-2009 & Major hazard identification standard & $\begin{array}{l}\text { State Administration } \\
\text { of work safety }\end{array}$ & $\begin{array}{l}\text { General } \\
\text { standards }\end{array}$ \\
\hline AQ8003-2007 & $\begin{array}{l}\text { Guidelines for safety acceptance and } \\
\text { evaluation }\end{array}$ & $\begin{array}{l}\text { State Administration } \\
\text { of work safety }\end{array}$ & $\begin{array}{l}\text { General } \\
\text { standards }\end{array}$ \\
\hline CB 3515-1993 & Ship construction safety management & $\begin{array}{l}\text { State Administration } \\
\text { of work safety }\end{array}$ & $\begin{array}{l}\text { Industry } \\
\text { standard }\end{array}$ \\
\hline--- & $\begin{array}{l}\text { Basic requirements for safety } \\
\text { production of ship repair and } \\
\text { construction enterprises }\end{array}$ & $\begin{array}{l}\text { Zhejiang Provincial } \\
\text { People's Government }\end{array}$ & $\begin{array}{l}\text { Local } \\
\text { industry } \\
\text { standards }\end{array}$ \\
\hline & $\begin{array}{l}\text { Measures of Guangdong Province on } \\
\text { safety production standardization } \\
\text { assessment of Ship building and } \\
\text { repairing enterprises }\end{array}$ & $\begin{array}{l}\text { Guangdong } \\
\text { Provincial People's } \\
\text { Government }\end{array}$ & $\begin{array}{l}\text { Local } \\
\text { industry } \\
\text { standards }\end{array}$ \\
\hline--
\end{tabular}

According to the authority standard of selection and the principle of "seven steps", this paper combines the definition of class attribute and facet definition, and build ontology model in the field of enterprise safety management.

\subsubsection{Domain and Scope of Ontology}

The first step in "seven step" is to clarify the domain and scope which is mainly related to the questions below:

(1) What is the domain that the ontology will cover?

Answer: The safety manangement in ship building and repairing enterprise.

(2)For what we are going to use the ontology?

Answer: We will use this ontology to support the tool development to rapidly bulid and verify the safety management ability of MIS in ship building and repairing enterprise.

(3) For what types of questions the information in the ontology should provide answers?

Answer: The ontology proposed in this paper may answer the error in the instance build by this ontology and the related tool.

(4) Who will use and maintain the ontology?

Answer: The MIS developer and system maintenance personnel.

(5) What are the professional competency problems the ontology can answer?

Answer: The ontology can support basic check such as concepts and relations in instance, and safety requirement verification based on axioms sets. 


\subsubsection{Consider Reusing Existed Ontology}

At present, there is no standard and recognized safety management ontology of ship building and repairing enterprise. Some exsited ontology are oriented to enterprise [22] or its architecture [23] without considering safety management and lack the description of safety constraints. Other related researches are oriented to fields as mine safety integration [24], nuclear power operation procedure [25]. Literature [26] used Protégé to build ontology and used prolog to analysis the activities in the shipbuilding fabrication process.

This paper adopt the geneal enterprise ontology in those literatures and combed the classes, associations, axioms to build an ontology oriented to safety management of shipbuilding and repairing enterprise.

\subsubsection{Enumerate Important Terms in Ontology}

This paper analyzed the related standards and enumerate some important terms listed in Table 2.

Table 2. Important terms in standards

\begin{tabular}{|c|c|}
\hline Terms & Standard \\
\hline work safety standardization & Basic norms for standardization of enterprise safety management \\
\hline safety performance & Basic norms for standardization of enterprise safety management \\
\hline interested party & Basic norms for standardization of enterprise safety management \\
\hline resources & Basic norms for standardization of enterprise safety management \\
\hline hazardous substance & Major hazard identification standard \\
\hline unit & Major hazard identification standard \\
\hline threshold quantity & Major hazard identification standard \\
\hline major accident & Major hazard identification standard \\
\hline major hazard installations & Major hazard identification standard \\
\hline hazard elements & $\begin{array}{l}\text { Basic requirements for safety production of ship repair and } \\
\text { construction enterprises }\end{array}$ \\
\hline safety evaluation & $\begin{array}{l}\text { Basic requirements for safety production of ship repair and } \\
\text { construction enterprises }\end{array}$ \\
\hline hazard cause & $\begin{array}{l}\text { Basic requirements for safety production of ship repair and } \\
\text { construction enterprises }\end{array}$ \\
\hline steel ships & $\begin{array}{l}\text { Basic requirements for safety production of ship repair and } \\
\text { construction enterprises }\end{array}$ \\
\hline displacement & $\begin{array}{l}\text { Basic requirements for safety production of ship repair and } \\
\text { construction enterprises }\end{array}$ \\
\hline LNG Ship & $\begin{array}{l}\text { Basic requirements for safety production of ship repair and } \\
\text { construction enterprises }\end{array}$ \\
\hline
\end{tabular}




\subsubsection{Class and Hierarchy}

Based on the analysis of the knowledge in the field of enterprise safety production management, from the top-level concept to the bottom, this paper gradually refined the classes in safety ontology of MIS, and established category and hierarchy in the field of safety production management as shown in Fig. 3.

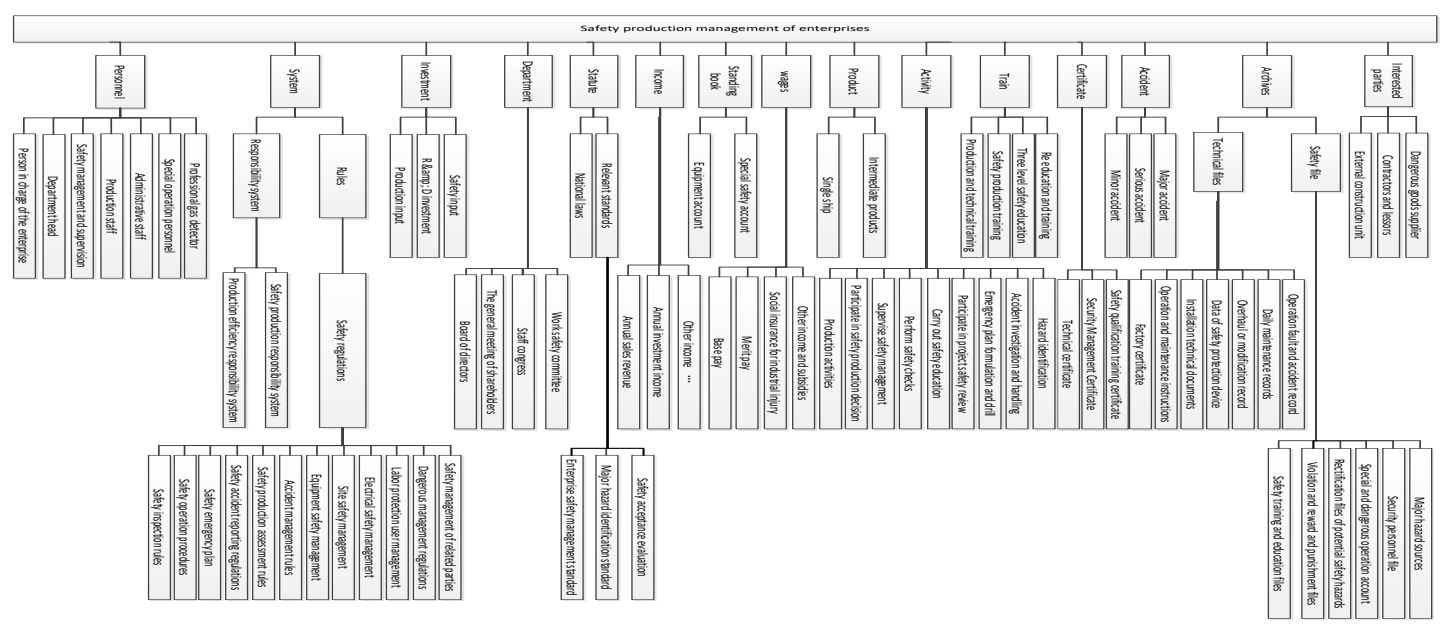

Fig. 3. Class and hierarchy

\subsubsection{Define the Properties of Classes-Slots}

This paper defined the properties of classes and turned them into the fields of data tables in the database created based on the ontology, and defined the extrinsic properties and relations to other individuals and turned them into the relation tables. A partial summary view of classes and associations was shown in Fig. 4.

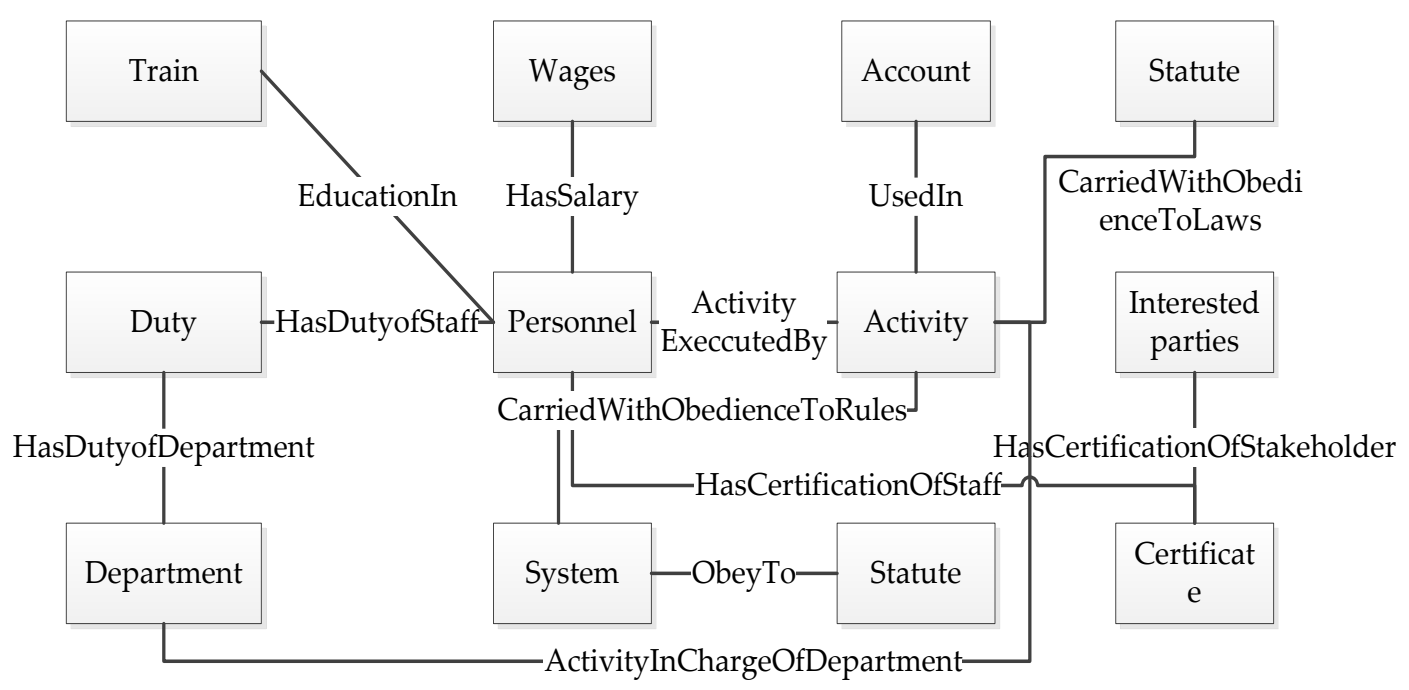

Fig. 4. Partial view of classes and associations 


\subsubsection{Define the Facets of the Slots}

This paper defined the facets and turened them into the constrains of fields in data tables.

\subsubsection{Create Instances}

An instance can be created based on the ontology built by six steps above. This paper created parts of an instance with verificaion as experiments in section 6 .

\subsection{Verification}

In Section 4.2, this paper established the safety ontology model including class and hierarchy, class attribute and facet, class and association, which is used to describe the constraints in the field of enterprise safety production management. It will then use the concept and association of ontology to form the axiom set, and also make the basic preparation for the database design and query verification on the safety of MIS.

\subsubsection{SHIQ}

SHIQ is a subset of predicate logic used to describe concepts and their hierarchical relationships, which has a complete and correct reasoning algorithm [21]. Description logic is more suitable for ontology engineering construction and reasoning test than first-order predicate logic, including conjunction, disjunction, existential quantifier, full name quantifier, negation, quantitative constraint and other construction factors. It is expanded by adding quantitative limiting factors, and it is also the formal basis of mainstream ontology reasoning engine.

There are some other ontology language used to be a description like OWL and OCL. When we used OWL or OCL, it is more meaningful and convenient to use related tools like Protégé or UML Tool to modeling and verification. This paper used SHIQ logic as a description of rules based on axioms in ontolgy, and turned those rules into SQL sentence to support verification. Considering that we developed own tool to modeling and verification and did not use exsited tools, so this paper used SHIQ as a formal description of axioms to be a bridge to SQL sentence.

\subsubsection{Verification Method and Process}

This paper turned the ontology concept set into the data table, and association to relation table of safety MIS, described axiom set using SHIQ logic as the formal basis of verification query statement and turned it into SQL to support verification.

The SQL statement generated in this paper is a description of the axiom set of violating the safety ontology standard. If the query result is empty, it means that the information system has no record of violating, otherwise, it will get the result details of violating the safety axiom set of the information system $[26,27]$. Based on the details of violation, we can obtain the verification results to easily improve the models and responding data base. The verification method and process were shown in Fig. 5. 


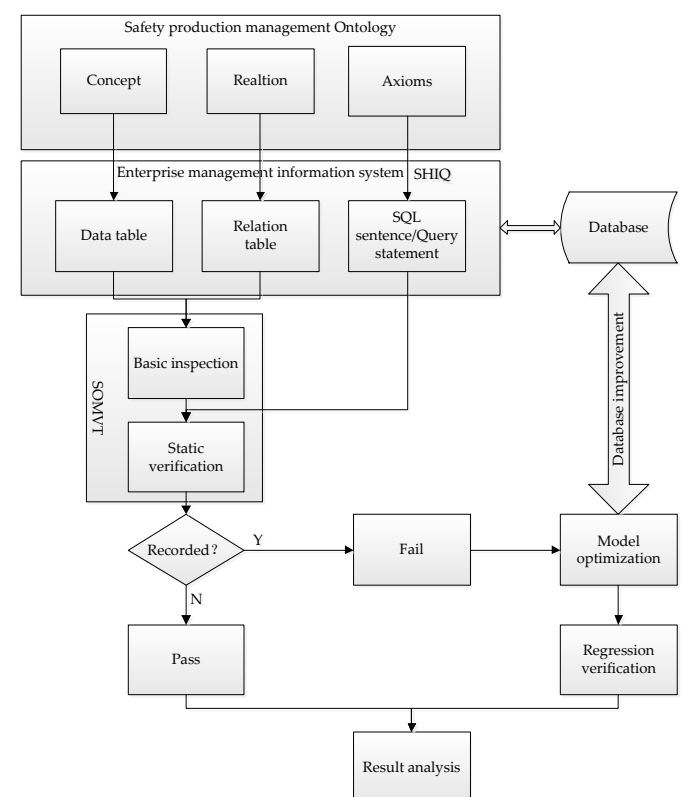

Fig. 5. Verification method and process

\section{Tool Design and Implementation}

This paper designed and implemented a safety modeling and verification tool based on ontology-SOMVT. SOMVT not only provides a friendly interface for the modeling and verification of MIS model on safety ontology, but also can greatly improves the verification efficiency and reusability.

\subsection{System Design and Main Interface}

SOMVT includes three main modules: management module, implementation module and database module. The system design and main interface are shown in Fig. 6. The main interface mainly includes the main modeling view area, project management area, safety process display area, modeling element selection area and information display area.

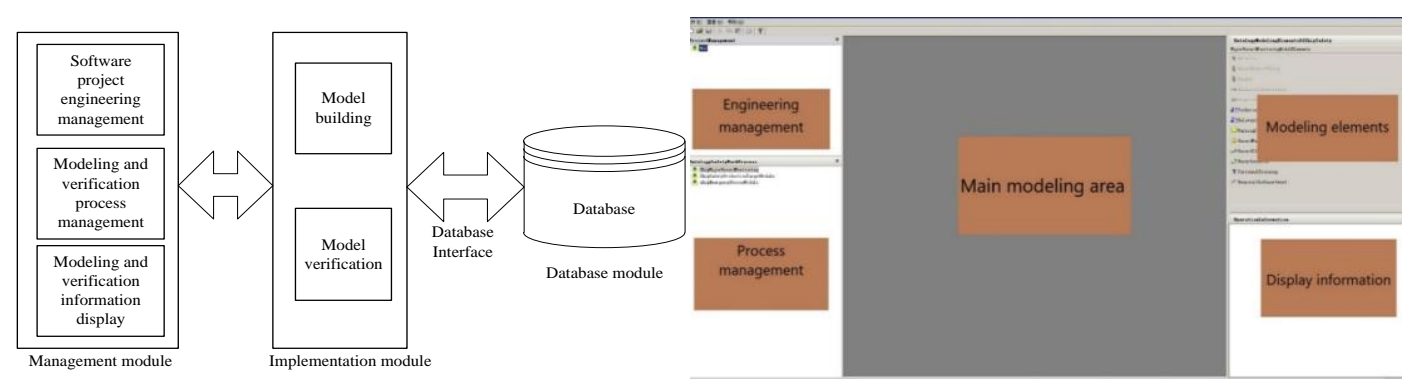

Fig. 6. System Design and Main Interface of SOMVT

\subsection{Visual Modeling}

The function of visual modeling mainly includes graphical class node and association modeling are shown in Fig. 7. SOMVT provides the easily drag operation to build node and 
association when modeling. With those operations, they are actual creation, modification and deletion operations on data table and associtation table in the database at the back of SOMVT.

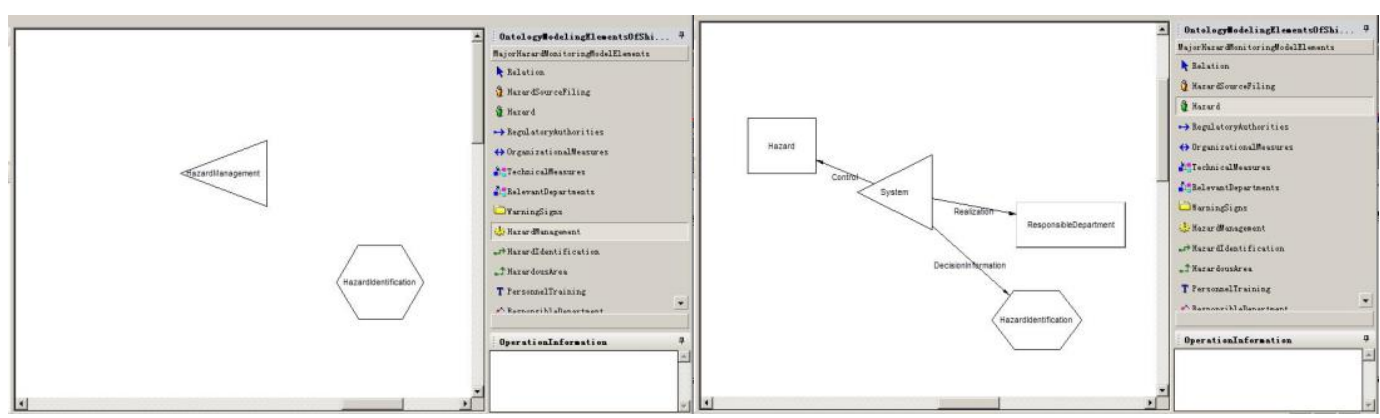

Fig. 7. Class Node and Association Modeling

\subsection{Design of Model Verification}

This paper built the instance model by visual modeling as dragging nodes and links between nodes, and excuted verification on SQL query. The action of dragging and editing nodes was correspongding to the instance edition of classes. The action of dragging and editing links between nodes was corresponding to the instance edition of associationes. The action of verificaion was corresponding to the excution of SQL query to find out the mistakes in the instance model.

Because the concepts and associations have been correctly defined in ontology model, and based on that, the tool in this paper can automatically stop and make tips of the wrong action as create nodes or relations not existed in ontology model instead of deleting or modifying the error operation. Of course, some mistakes in editing nodes or relations can be found by basic check as in Fig. 10. The mechnism of model verificaiton was shown in Fig. 8.

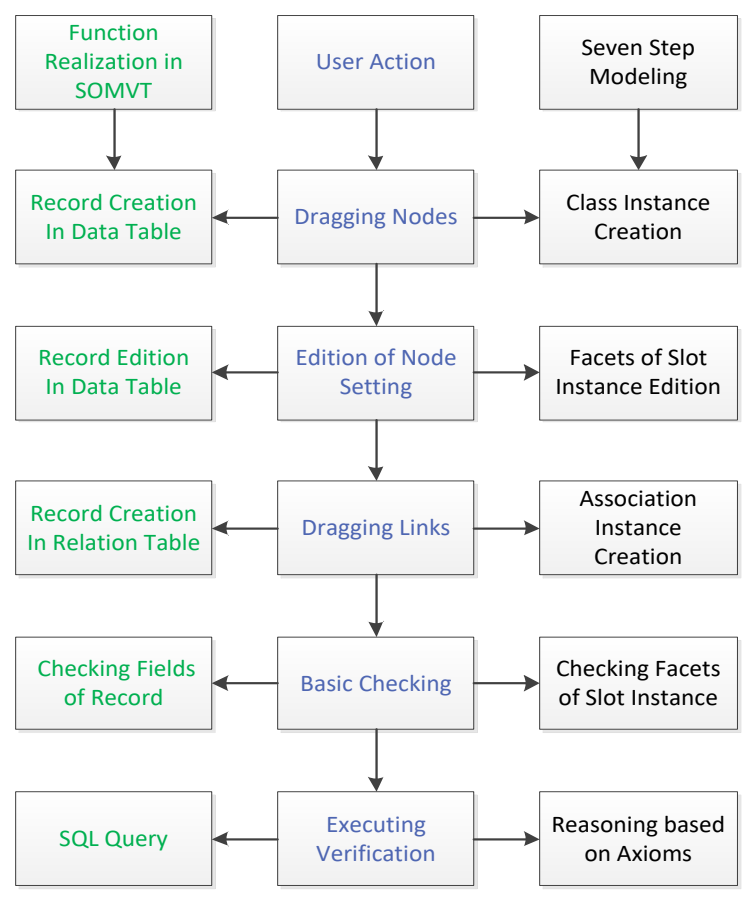

Fig. 8. Mechnism of Model Verification 
The model verification result of SOMVT and node modification is shown in Fig. 9. We can modify and improve the model based on the operation information supplied by this tool.

By the modification in the tool, there are automatic improvement on the database in the back at the same time.

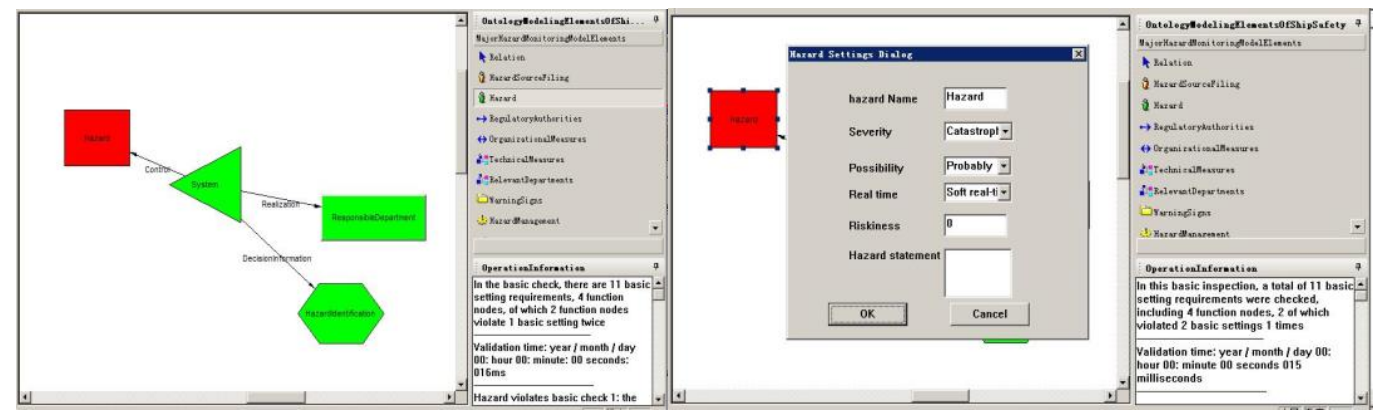

Fig. 9. Verification and Modification

\section{Experiments}

《Shipbuilding Safety Standardization》was proposed by the China State Administration of work safety and drafted in accordance with the rules given in GB/T1.1-2009(Directives for standardization - Part 1: Strucure and drafting of standards). It is under the unified management and implementation of the National Work Safety Standardization Technical Committee.

This paper made a detailed example of modeling, verification and improvement on major hazard monitoring, and made another concise example on target of safety production. There were two groups in the experiment, one using SOMVT and another in manual to implement the two examples. And then, this paper collected all the two experiments data to make a comparison and analysis between groups using SOMVT and in manual.

In the experiment, the data such as the time used for analysis and verification, the number of problems found, the number and time of modification and regression verification were recorded. The purpose of the experiment was to compare the number of problems found, the number of regression verification and the efficiency of verification between the safety analysis using SOMVT and the mannual safety analysis, to prove the effectiveness and efficiency of ontology modeling methodology with the SOMVT.

The experiment was divided into two groups $\mathrm{A}$ and $\mathrm{B}$, and two in each group, four in total. Group A used the SOMVT to implement automatic modeling and verification, while group B used traditional manual inspection and analysis. The information of the participants was shown in Table 3.

Table 3. Group Information

\begin{tabular}{|c|c|c|c|c|}
\hline Group & Number & Grade & Skilled time & Using SOMVT \\
\hline \multirow{2}{*}{ A } & A1 & Graduates of Grade 3 & One year & Yes \\
\cline { 2 - 5 } & A2 & Graduates of Grade 2 & Three months & Yes \\
\hline \multirow{2}{*}{ B } & B1 & Graduates of Grade 3 & One year & No \\
\cline { 2 - 5 } & B2 & Graduates of Grade 2 & Three months & No \\
\hline
\end{tabular}




\subsection{Major Hazard Monitoring}

Major hazard monitoring is an important part of 《Shipbuilding Safety Standardization》, which is the link between daily management of major hazard, accident prevention and emergency rescue. In the major accident prevention and emergency rescue system, the monitoring of major hazard sources also has very high importance [29, 30].

\subsubsection{Modeling}

\section{1) Node Creation}

This paper extracted the professional terms of the major hazard monitoring and generated the corresponding model. The creation of nodes in the tool is inseparable from the class and hierarchy. The professional terms and types in the initial major hazard monitoring are shown in Table 4. It can be seen from the table that 12 professional terms and corresponding class names are included in the class and hierarchy of major hazard monitoring, which requires at least 12 nodes to be created in the SOMVT.

Table 4. Node Creation

\begin{tabular}{|c|c|}
\hline Node & Class \\
\hline Hazard & Danger \\
\hline Hazard management regulation & Information \\
\hline Responsible Department & Department \\
\hline Hazardous Area & Information \\
\hline Hazard Identification & Information \\
\hline Hazard Filing & Function \\
\hline Regulatory Authorities & Department \\
\hline Relevant Departments & Department \\
\hline Technical Measures & Operation \\
\hline Organizational Measures & Operation \\
\hline Personnel Training & Operation \\
\hline Warning Signs & Information \\
\hline
\end{tabular}

\section{2) Relation Creation}

Nodes and relations are the bases to describle axioms that will be used to safety verification. The relations, source class nodes and target class nodes in the original model of major hazard monitoring module were summarized in Table 5. If the relation is created by dragging from source class nodes to target class nodes, then a record is automatically created in the corresponding association tables in database of SOMVT.

Table 5. Associations in major hazard monitoring

\begin{tabular}{|c|c|c|}
\hline Association & Source node & Target node \\
\hline Realization & Responsible Department & $\begin{array}{c}\text { Hazard management } \\
\text { regulation }\end{array}$ \\
\hline Decision Information & $\begin{array}{c}\text { Hazard management } \\
\text { regulation }\end{array}$ & Hazard Identification \\
\hline Decision Information & $\begin{array}{c}\text { Hazard management } \\
\text { regulation }\end{array}$ & Hazardous Area \\
\hline
\end{tabular}




\begin{tabular}{|c|c|c|}
\hline Activation & Hazard & Hazard Filing \\
\hline Monitor & Regulatory Authorities & Hazard \\
\hline Monitor & Relevant Departments & Hazard \\
\hline Realization & $\begin{array}{c}\text { Hazard management } \\
\text { regulation }\end{array}$ & Technical Measures \\
\hline Realization & $\begin{array}{c}\text { Hazard management } \\
\text { regulation }\end{array}$ & Organizational Measures \\
\hline Realization & Organizational Measures & Personnel Training \\
\hline Relieve & Technical Measures & Hazard \\
\hline Relieve & Organizational Measures & Hazard \\
\hline Decision Information & Hazard & Warning Signs \\
\hline
\end{tabular}

\section{3) Original Modeling}

Major hazard monitoring is a detailed instance for modeling and verification in this paper. The original model of major hazard monitoring was shown in Fig. 10.

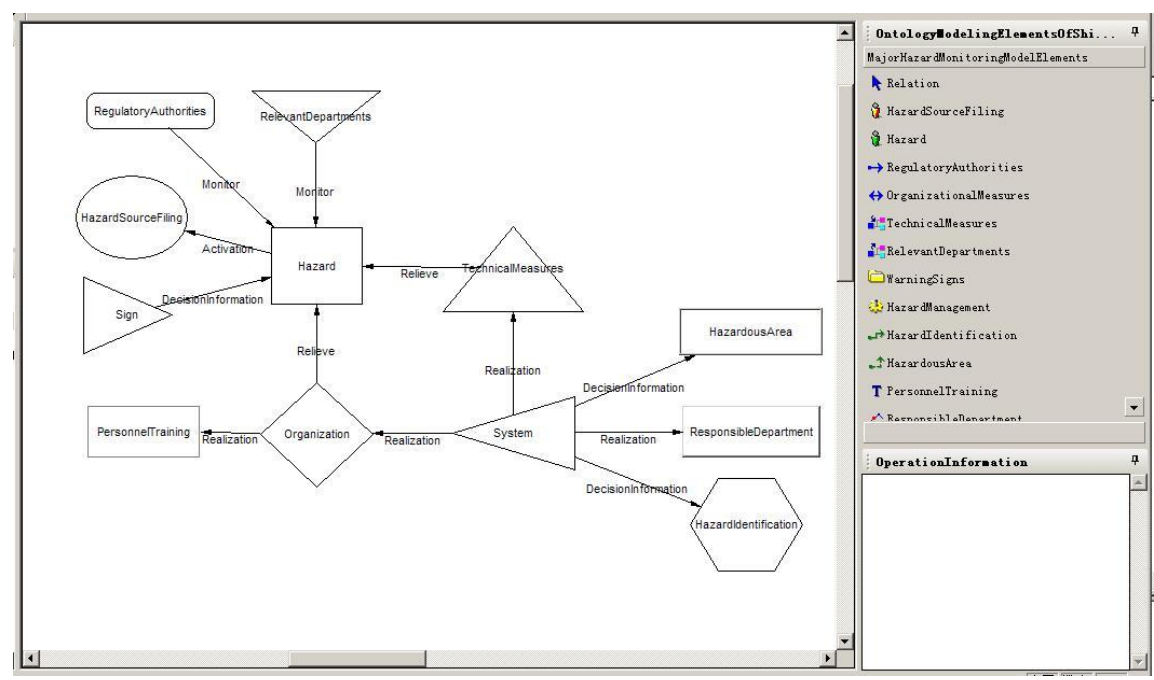

Fig. 10. Original Model

\subsubsection{Safety Verification}

The verification process mainly includes basic check, verification requirement creation, and verification implemention. Regression verification is the process of optimizing and reverifying the model based on the problem analysis of the verification result.

\section{1) Basic Check}

Basic check is an essential process for nodes before model verification which includes the attribute information of nodes, whether the class and hierarchy settings are correct, whether the class and association settings are correct, etc. Nodes that fail to pass the basic check will in red waiting for modification.

The completion of basic check of original model was shown in Fig. 11. 


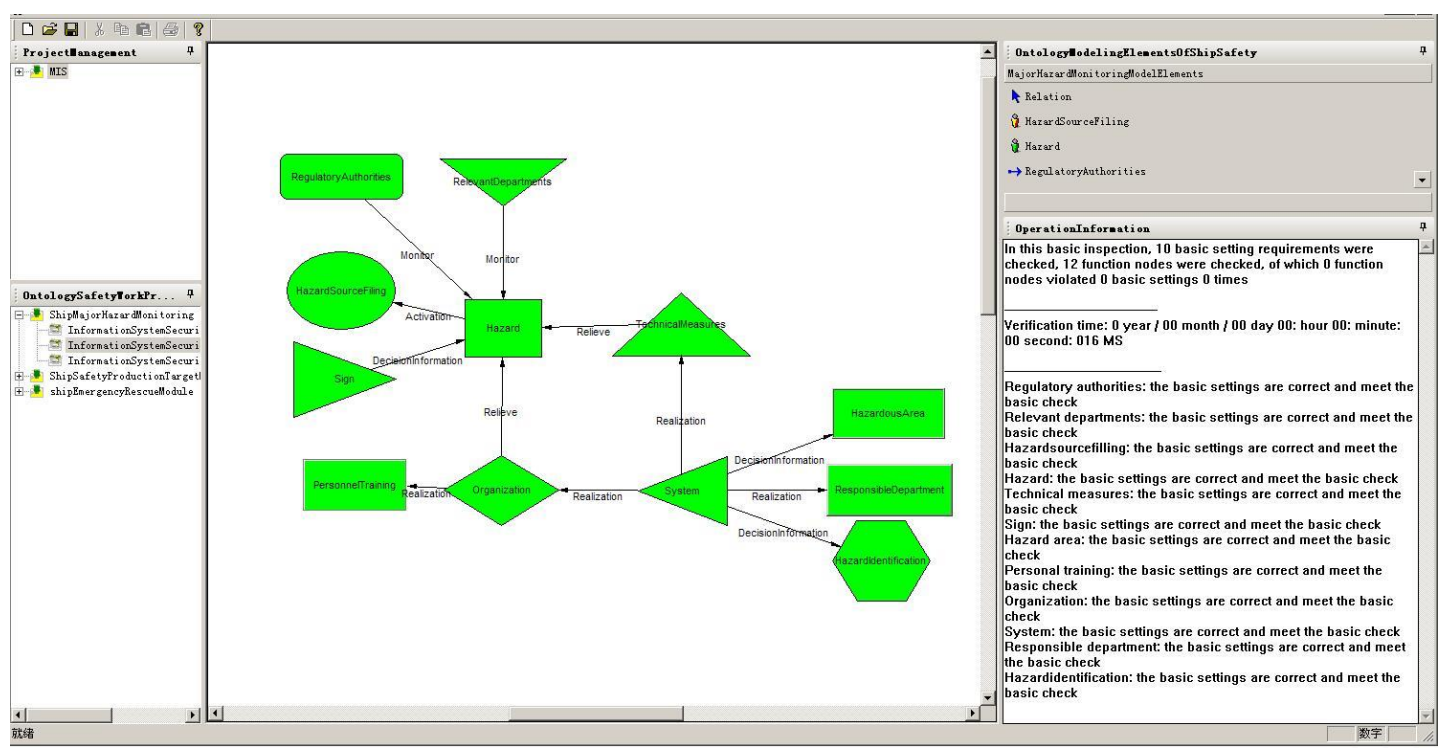

Fig. 11. Basic Check of Original Model

\section{2) Requirements Verification}

Requirement Verification refers to the axiom set in safety ontology of Shipbuilding and repair MIS, which extracted from standards as listed in Table 1 and describled by SHIQ logic from natural language interpretation.

Two examples of requirements extracted from safety standards and their corresponding SHIQ descriptions with SQL statements were shown in Table 6 and Table 7:

Table 6. Example1 of requirements

\begin{tabular}{|c|c|}
\hline $\begin{array}{l}\text { Verification } \\
\text { requirements }\end{array}$ & $\begin{array}{l}\text { Hazard source filing must have the functions of hazard source identification, } \\
\text { hazard range, responsible department, etc. }\end{array}$ \\
\hline $\begin{array}{l}\text { SHIQ } \\
\text { Description }\end{array}$ & 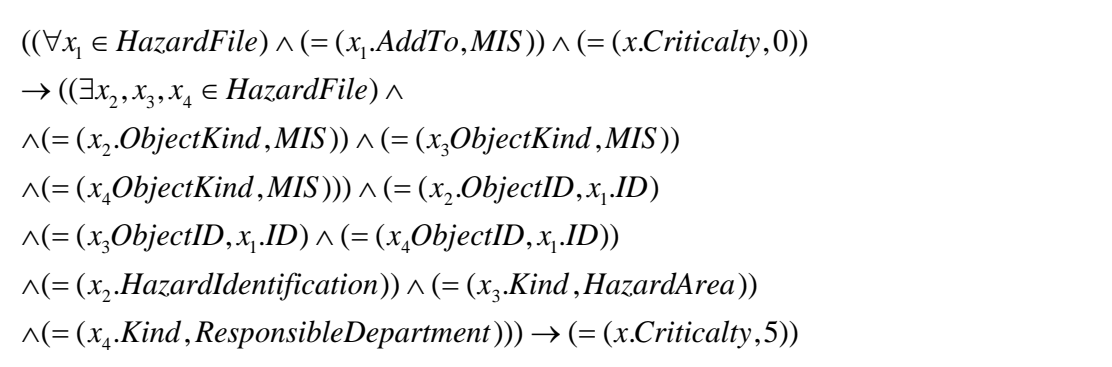 \\
\hline SQL & $\begin{array}{l}\text { SELECT f1.Name, f1.Key } \\
\text { FROM tb_HazardFile AS f1, tb_Hazard AS h, tb_HazardFileRelatedToHazard } \\
\text { AS frh } \\
\text { WHERE f1.Criticality }>0 \text { and f1.Criticality }<5 \text { and frh.RelatedKind }>0 \text { and frh. } \\
\text { HazardFileID=f1. HazardFile_ID and frh.HazardID=h.Hazard_ID and f1. } \\
\text { HazardFile_ID not in (select f1. HazardFile_ID from tb_HazardFileRelatedTo } \\
\text { HazardFile as frf,tb_HazardFile as f2 where frf. HazardFileOrgID=f2. } \\
\text { HazardFile_ID and frf. HazardFileDstID=f1. HazardFile_ID and } \\
\text { frf.RelatedKind=5); }\end{array}$ \\
\hline
\end{tabular}


Table 7. Example2 of requirements

\begin{tabular}{|c|c|}
\hline $\begin{array}{l}\text { Verification } \\
\text { requirements }\end{array}$ & There must be at least one hazard management regulation for each hazard source. \\
\hline $\begin{array}{l}\text { SHIQ } \\
\text { Description }\end{array}$ & $\begin{array}{l}\forall(x \in \text { Hazard }) \rightarrow((\exists y \in \text { HazardSour ce Re lationEnti ty }) \wedge(y . I D, X . I D))) \\
\wedge(=(y . \text { Kind }, \text { HazardMana gement Re gulation })))\end{array}$ \\
\hline SQL Sentence & $\begin{array}{l}\text { SELECT f1.Function_ID, f1.Name, f1.Key } \\
\text { FROM tb_Function AS f1, tb_Hazard AS h, tb_FunctionRelatedToHazard AS frh } \\
\text { WHERE frh.HazardID=h.Hazard_ID and frh.FunctionID=f1.Function_ID and } \\
\text { frh.RelatedKind=1 and f1.Function_ID not in(select f1.Function_ID from } \\
\text { tb_Function as f2,tb_FunctionRelatedToFunction as frf where frh.RelatedKind=1 } \\
\text { and frf.FunctionDstID=f1.Function_ID and frf.FunctionOrgID=f2.Function_ID); }\end{array}$ \\
\hline
\end{tabular}

\section{3) Verification}

The verification process is to query and verify the concepts and relations in the original model through the SQL query statement based on the axiom set, and then generate the verification result. In the view of SOMTV, the passed models are in green, and the nodes breaking axioms are warned in red. The verification results of original model were shown in Fig. 12. According to the verification results shown in operation information in SOMVT, 12 nodes were verified in the model, 9 of which failed to pass the verification with 18 violations.

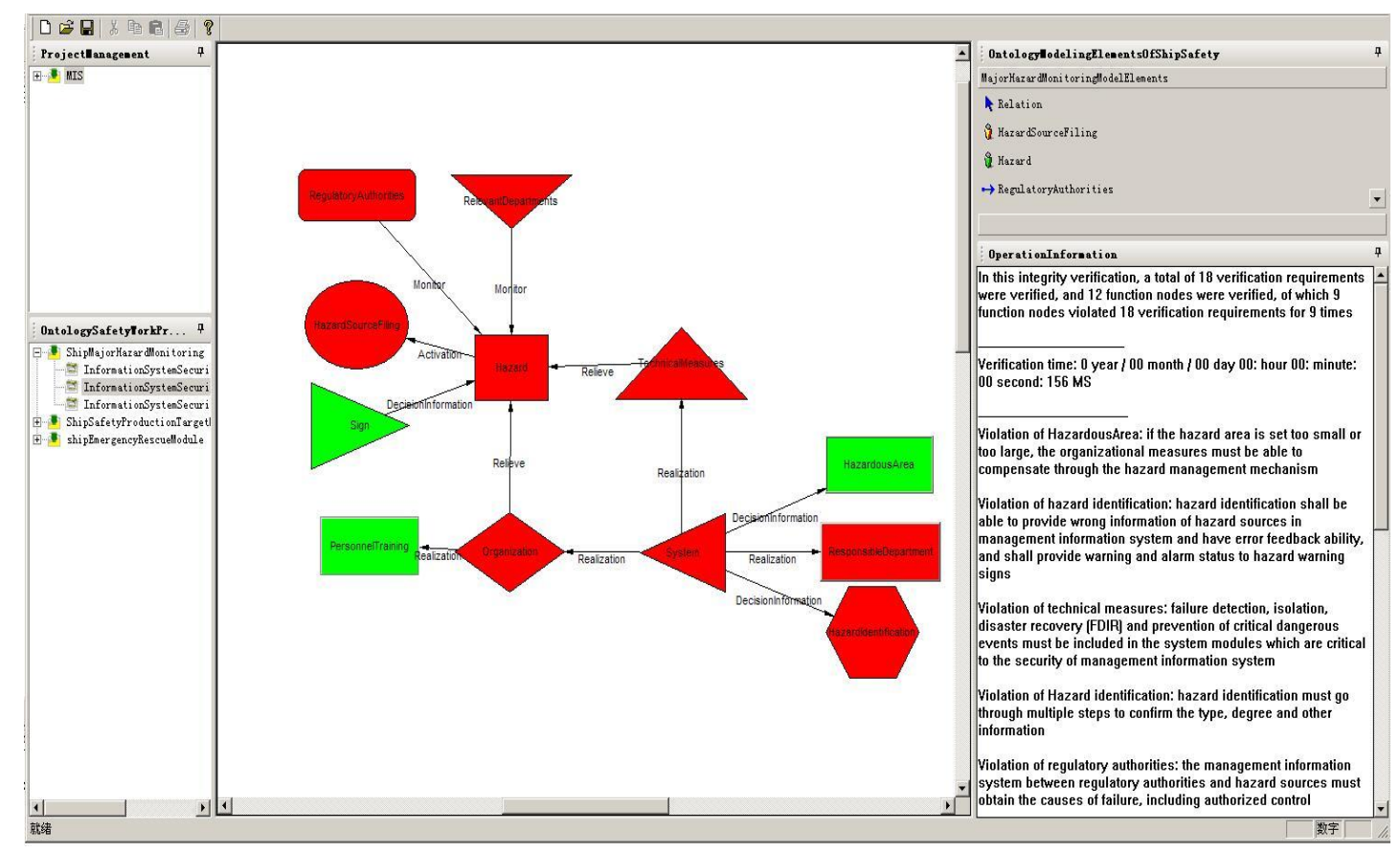

Fig. 12. Model Verification Results

\section{4) Problems Analysis}

By the analysis of the verification requirements violated, there were 18 safety violations. The detailed descriptions of the violation were shown in Table 8 as the same in SOMVT.

The verification report contained the problems existing in the model of major hazard monitoring, including rules, logic, functions and other aspects. The discovery of these 
problems proved the necessity of modeling and verifying the safety of the major hazard monitoring module by related ontology theories and modeling methods proposed in this paper.

Table 8. Verification Result of Original Model

\begin{tabular}{|c|c|}
\hline Number & Verification Result \\
\hline 1 & $\begin{array}{l}\text { Violation of hazardous area: if the hazardous area is set too small or too } \\
\text { large, the organizational measures must be able to compensate through the } \\
\text { hazard source management mechanism }\end{array}$ \\
\hline 2 & $\begin{array}{l}\text { Violation of hazard identification: hazard identification shall be able to } \\
\text { provide error information of hazard sources of management information } \\
\text { system and have error feedback ability, and provide warning and alarm } \\
\text { status to hazard warning signs }\end{array}$ \\
\hline 3 & $\begin{array}{l}\text { Violation of technical measures: the safety critical system modules of } \\
\text { management information system must have failure detection, isolation, } \\
\text { disaster recovery (FDIR) and prevent the occurrence of critical dangerous } \\
\text { events }\end{array}$ \\
\hline 4 & $\begin{array}{l}\text { Regulatory violations: safety critical MIS modules must have failure } \\
\text { detection, isolation, disaster recovery (FDIR) and prevention of critical } \\
\text { hazardous events }\end{array}$ \\
\hline 5 & $\begin{array}{l}\text { Violation of hazardous area: the management information system must be a } \\
\text { known safety critical system, so as to realize automatic failure detection, } \\
\text { isolation and recovery of hazardous area in different time periods }\end{array}$ \\
\hline 6 & $\begin{array}{l}\text { Violation of hazard identification: hazard identification must go through } \\
\text { multiple steps to confirm the type, degree and other information }\end{array}$ \\
\hline 7 & $\begin{array}{l}\text { Violation by the regulatory authority: the management information system } \\
\text { between the regulatory authority and the hazard source must obtain the } \\
\text { reasons for failure, including authorized control executor, specific operator } \\
\text { or operation action }\end{array}$ \\
\hline 8 & $\begin{array}{l}\text { Violation of hazard source filing: there must be reasons for failure from } \\
\text { hazard source filing to hazard source, including authorized control executor, } \\
\text { specific operator or operation action }\end{array}$ \\
\hline 9 & $\begin{array}{l}\text { Violation by the responsible department: the responsible department shall } \\
\text { have the following functions in the hazard management regulation, } \\
\text { including hazard identification, taking technical measures to remedy and } \\
\text { setting warning signs }\end{array}$ \\
\hline 10 & $\begin{array}{l}\text { Violation of hazard source: the hazard source shall provide warning and } \\
\text { alarm status to the construction personnel, equipment operators or control } \\
\text { executives }\end{array}$ \\
\hline 11 & $\begin{array}{l}\text { Violation of technical measures: technical measures shall provide means for } \\
\text { constructors or control executors to enforce automatic safety protection, } \\
\text { fault isolation or switching functions }\end{array}$ \\
\hline 12 & $\begin{array}{l}\text { Violation of hazard identification: hazard identification shall provide means } \\
\text { for construction personnel or control executors to enforce automatic safety } \\
\text { protection, fault isolation or switching functions }\end{array}$ \\
\hline 13 & $\begin{array}{l}\text { Violation of technical measures: technical measures shall provide operation } \\
\text { for construction personnel or control executors to return to the previous safe } \\
\text { state or mode }\end{array}$ \\
\hline
\end{tabular}




\begin{tabular}{|c|l|}
\hline $\mathbf{1 4}$ & $\begin{array}{l}\text { Violation of hazard identification: hazard identification shall provide } \\
\text { operation for construction personnel or control executors to return to the } \\
\text { previous safe state or mode }\end{array}$ \\
\hline $\mathbf{1 5}$ & $\begin{array}{l}\text { Violation by the responsible department: the responsible department shall } \\
\text { provide operation for the construction personnel or control executors to } \\
\text { return to the previous safety state or mode }\end{array}$ \\
\hline $\mathbf{1 6}$ & $\begin{array}{l}\text { Violation of technical measures: technical measures shall provide means for } \\
\text { constructors or control executors to enforce automatic safety protection, } \\
\text { fault isolation or switching functions }\end{array}$ \\
\hline $\mathbf{1 7}$ & $\begin{array}{l}\text { Violation by the responsible department: the responsible department shall } \\
\text { provide operation means for construction personnel or control executors to } \\
\text { forcibly perform automatic safety protection, fault isolation or switching } \\
\text { functions }\end{array}$ \\
\hline $\mathbf{1 8}$ & $\begin{array}{l}\text { Violation of hazard identification: hazard identification shall provide means } \\
\text { for construction personnel or control executors to forcibly perform } \\
\text { automatic safety protection, fault isolation or switching functions }\end{array}$ \\
\hline
\end{tabular}

\subsubsection{Model Improvement and Regression}

Taking 11 in Table 7 of the model verification results as an example, the technical measures should provide the means to implement automatic safety protection, fault isolation or switching function for the construction personnel or control execution personnel.

In the original model, technical measures only have an impact on hazard sources and hazard source management system, and do not play an effective role in technical monitoring, problem solving and hazard investigation, so they can only play a limited role. In the actual production environment, technical measures should not only comply with the relevant technical standards and laws and regulations, but also have a positive impact on the actual production environment, which can ensure that the production environment is maintained in a good state. At the same time, they should be used in the activities of condition monitoring, equipment debugging, production process optimization, etc., to ensure the stability of equipment and the safety of personnel.

Therefore, the influence scope of technical measures should be improved. In the model optimization, the technical measures should be provided with hazard identification with safety assessment as the intermediate process; application license system with equipment detection as the intermediate process; hazard identification with hazard management system as the intermediate process, so as to promote the association of the whole system, strengthen the interaction between nodes, and make the whole system stable. So we should add nodes and Assocication as in Table 9 and Table 10.

Table 9. Nodes Added to 11

\begin{tabular}{|c|c|}
\hline Node Added & Concept \\
\hline Safety Assessment & Operation \\
\hline User License & Information \\
\hline
\end{tabular}

Table 10. Associations Added to 11

\begin{tabular}{|c|c|c|}
\hline Association & Source node name & Target node name \\
\hline Produce & Hazard Identification & Hazardous Facilities \\
\hline
\end{tabular}


According to the verification results, the original model was optimized by adding 7 nodes and 18 associations. In technical, the added nodes and associations are responding to adding data tables records and association tables records in the data base of original model. Those improvements on data tables and association tables are actually improvements on orignal data base. The added nodes and class type were shown in Table 11, and the relationships added between nodes were shown in Table 12.

Table 11. Nodes Added to Original Model

\begin{tabular}{|c|c|}
\hline Node Added & Concept \\
\hline Safety Assessment & Operation \\
\hline User License & Information \\
\hline Hazardous Facilities & Hardware \\
\hline Testing Equipment & Hardware \\
\hline Switch Confirmation & Operation \\
\hline Forced Termination & Function \\
\hline Enforcement & Operation \\
\hline
\end{tabular}

Table 12. Associations Added to Original Model

\begin{tabular}{|c|c|c|}
\hline Association & Source node name & Target node name \\
\hline Monitor & Forced Termination & Hazard \\
\hline Monitor & Use License & Regulatory Authorities \\
\hline Monitor & Use License & Hazardous Facilities \\
\hline Decision Information & Use License & Testing Equipment \\
\hline Monitor & Switch Confirmation & Forced Termination \\
\hline Monitor & Switch Confirmation & Regulatory Authorities \\
\hline Monitor & Switch Confirmation & Enforcement \\
\hline Control & Switch Confirmation & Hazard \\
\hline Decision Information & Switch Confirmation & Hazard management regulation \\
\hline Union & Switch Confirmation & Responsible Department \\
\hline Decision Information & Safety Assessment & Hazard \\
\hline Execute & Regulatory Authorities & Forced Termination \\
\hline Cause & Technical Measures & Safety Assessment \\
\hline Realization & Technical Measures & Testing Equipment \\
\hline Union & Organizational Measures & Regulatory Authorities \\
\hline Monitor & Hazard management regulation & Enforcement \\
\hline Decision Information & Hazard management regulation & Hazardous Facilities \\
\hline Produce & Hazard Identification & Hazardous Facilities \\
\hline
\end{tabular}

The optimized model consists of 19 nodes and 31 associations which means there are 19 new data table records and 31 new assocication table records in the improved MIS. The verification results of the optimized model are shown in Fig. 13. 


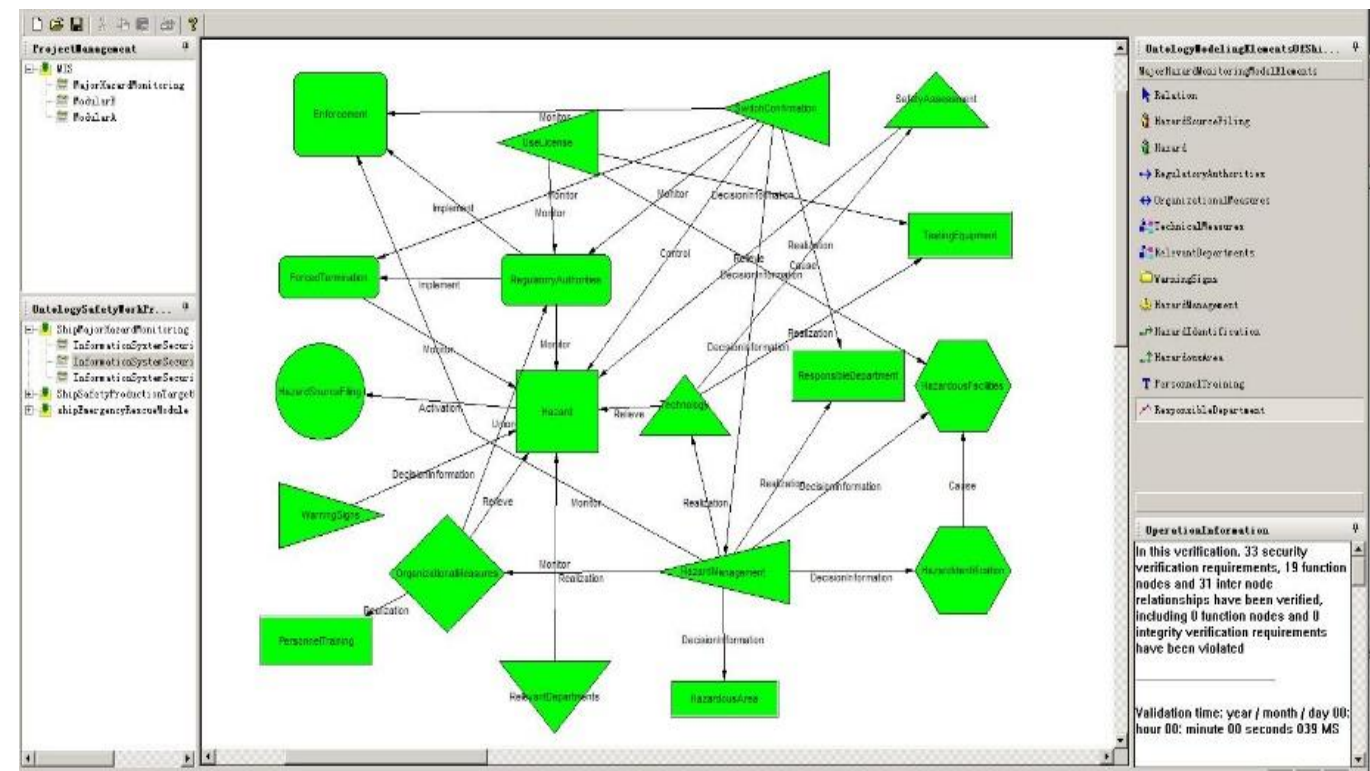

Fig. 13. Regression Verification Results

According to the regression verification results, the improved model can effectively control, constrain or authorize the nodes and associations to deal with safety problems. The optimized model can effectively deal with the safety risks on the basis of completing the basic functions, and improve the safety ability of MIS.

\subsection{Target of Safety Production}

This paper made a concise example of Target of Safety Production as shown in below. Target of Safety Production included monitoring, record, and evalution on target of safety production.

\subsubsection{Modeling and Verification}

This paper modeled and made verification on Target of Safety Production by SOMVT. There were 6 nodes that brook 6 verification requirement in 9 times which was shown in Fig. 14.

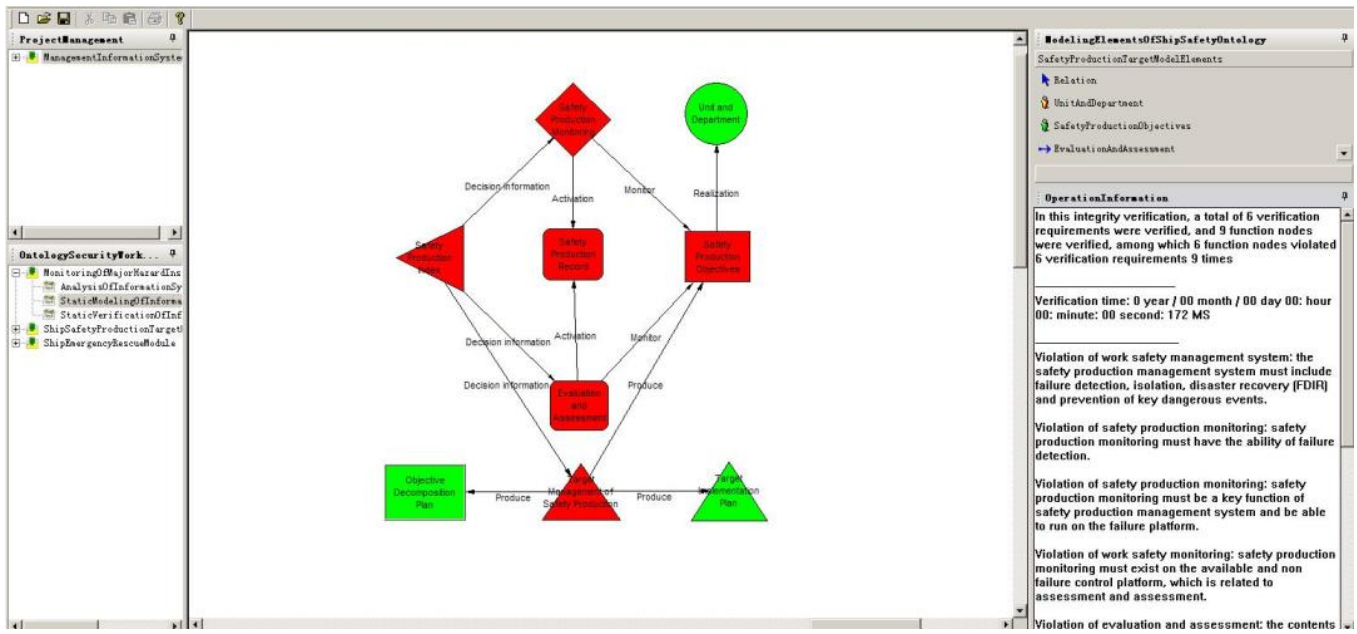

Fig. 14. Result of Modeling and Verification on Target of Safety Production 


\subsubsection{Improvement and Regression}

This paper added 7 nodes and 10 associations to the original model according to the verification result, and passed the regression by improvement as shown in Fig. 15 .

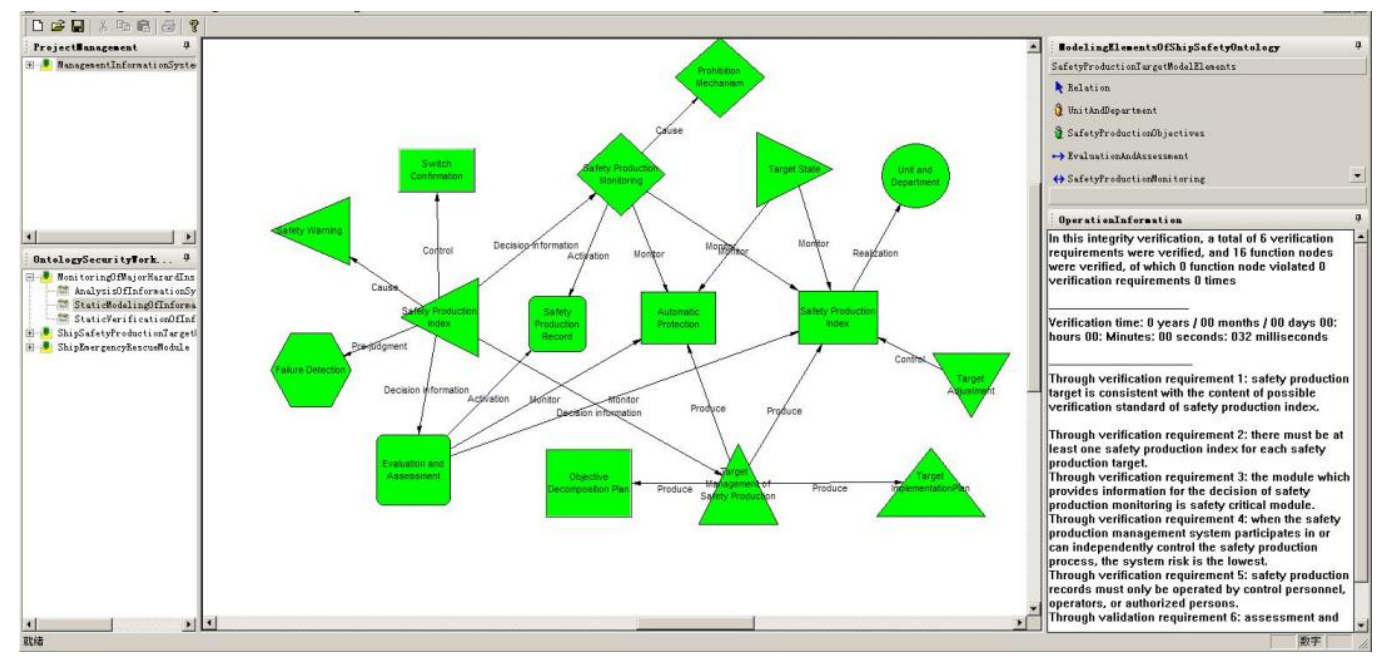

Fig. 15. Regression Result of Target of Safety Production

\subsection{Comparison and Analysis}

\subsubsection{Major Hazard Monitoring}

In the experiment process, there was 18 problems in the model and the data was recorded as follows. Table 13 showed the time spent in modeling, basic check, safety verification and the number of problems found of for $\mathrm{A} 1$ in group $\mathrm{A}$.

Table 13. A1 Data Record-Major Hazard Monitoring

\begin{tabular}{|c|c|c|c|c|c|}
\hline Process & $\begin{array}{l}\text { Modeling time } \\
\text { (second) }\end{array}$ & $\begin{array}{l}\text { Basic check } \\
\text { time (second) }\end{array}$ & $\begin{array}{l}\text { Verification } \\
\text { time (second) }\end{array}$ & $\begin{array}{l}\text { Total time } \\
\text { (second) }\end{array}$ & $\begin{array}{l}\text { Problems } \\
\text { found }\end{array}$ \\
\hline Original Modeling & 67 & 0.35 & 0.77 & 68.12 & 18 \\
\hline Regression 1 & 95 & 0.47 & 0.86 & 96.33 & 0 \\
\hline Total & 162 & 0.82 & 1.63 & 164.45 & 18 \\
\hline \multicolumn{2}{|c|}{ Verification Time/Problems } & 9 & \multicolumn{2}{|c|}{ Ratio of Problem Finding } & $100 \%$ \\
\hline
\end{tabular}

Table 14 showed the time spent in modeling, basic check, safety verification and the number of problems found for A2 in group A.

Table 14. A2 Data Record-Major Hazard Monitoring

\begin{tabular}{|c|c|c|c|c|c|}
\hline Process & $\begin{array}{l}\text { Modeling time } \\
\quad \text { (second) }\end{array}$ & $\begin{array}{l}\text { Basic check } \\
\text { time (second) }\end{array}$ & $\begin{array}{l}\text { Verification } \\
\text { time (second) }\end{array}$ & $\begin{array}{l}\text { Total time } \\
\text { (second) }\end{array}$ & $\begin{array}{l}\text { Problems } \\
\text { found }\end{array}$ \\
\hline Original Modeling & 259 & 0.39 & 0.56 & 259.95 & 18 \\
\hline Regression 1 & 566 & 0.44 & 0.50 & 566.94 & 0 \\
\hline Total & 825 & 0.83 & 1.06 & 826.89 & 18 \\
\hline \multicolumn{2}{|c|}{ Verification Time/Problems(second) } & 45.8 & \multicolumn{2}{|c|}{ Ratio of Problem Finding } & $100 \%$ \\
\hline
\end{tabular}


Table 15 showed the analysis and inspection time of B1 in group B and the number of problems found. In the number of problems found, there was a negative number which means the B1 has wrongly found two problems and corrected them in the end.

Table 15. B1 Data Record-Major Hazard Monitoring

\begin{tabular}{|c|c|c|c|c|}
\hline Process & $\begin{array}{c}\text { Analysis time } \\
\text { (second) }\end{array}$ & $\begin{array}{c}\begin{array}{c}\text { Verification time } \\
\text { (second) }\end{array} \\
\end{array}$ & Total time (second) & $\begin{array}{c}\text { Problems } \\
\text { found }\end{array}$ \\
\hline Original Modeling & 416 & 206 & 622 & 10 \\
\hline Regression 1 & 963 & 233 & 1196 & 2 \\
\hline Regression 2 & 322 & 548 & 870 & 4 \\
\hline Regression 3 & 125 & 108 & 233 & -2 \\
\hline Total & 1826 & 1095 & 2921 & 14 \\
\hline \multicolumn{2}{|c|}{ Verification Time/Problems(second) } & 130.43 & Ratio of Problem Finding & $77.78 \%$ \\
\hline
\end{tabular}

Table 16 showed the analysis and check time of B2 in group B and the number of problems found. In the number of problems found, there were negative numbers which means the B2 had wrongly found many problems and corrected them more than one time in the end.

Table 16. B2 Data Record-Major Hazard Monitoring

\begin{tabular}{|c|c|c|c|c|}
\hline Process & $\begin{array}{c}\begin{array}{c}\text { Analysis time } \\
\text { (second) }\end{array} \\
\end{array}$ & $\begin{array}{c}\begin{array}{c}\text { Verification time } \\
\text { (second) }\end{array} \\
\end{array}$ & Total time (second) & $\begin{array}{c}\text { Problems } \\
\text { found }\end{array}$ \\
\hline Original Modeling & 455 & 366 & 821 & 6 \\
\hline Regression 1 & 1036 & 294 & 1330 & 15 \\
\hline Regression 2 & 706 & 112 & 818 & -10 \\
\hline Regression 3 & 369 & 255 & 624 & -2 \\
\hline Regression 4 & 205 & 74 & 279 & 1 \\
\hline Regression5 & 178 & 162 & 340 & 1 \\
\hline Total & 2949 & 1263 & 4212 & 11 \\
\hline \multicolumn{2}{|c|}{ Verification Time/Problems(second) } & 268.1 & Ratio of Problem Finding & $61.11 \%$ \\
\hline
\end{tabular}

\subsubsection{Target of Safety Production}

There was 9 problems in the model and Table 17 showed the time spent in modeling, basic check, safety verification and the number of problems found of for A1 in group A.

Table 17. A1 Data record-Target of Safety Production

\begin{tabular}{|c|c|c|c|c|c|}
\hline Process & $\begin{array}{c}\text { Modeling } \\
\text { time (second) }\end{array}$ & $\begin{array}{l}\text { Basic check } \\
\text { time (second) }\end{array}$ & $\begin{array}{l}\text { Verification } \\
\text { time (second) }\end{array}$ & $\begin{array}{l}\text { Total time } \\
\text { (second) }\end{array}$ & $\begin{array}{l}\text { Problems } \\
\text { found }\end{array}$ \\
\hline Original Modeling & 46 & 0.33 & 0.81 & 47.14 & 9 \\
\hline Regression 1 & 44 & 0.45 & 0.79 & 45.24 & 0 \\
\hline Total & 90 & 0.78 & 1.6 & 92.38 & 9 \\
\hline \multicolumn{2}{|c|}{ Verification Time/Problems(second) } & 10.26 & \multicolumn{2}{|c|}{ Ratio of Problem Finding } & $100 \%$ \\
\hline
\end{tabular}


Table 18 showed the time spent in modeling, basic check, safety verification and the number of problems found for $\mathrm{A} 2$ in group $\mathrm{A}$.

Table 18. A2 Data record-Target of Safety Production

\begin{tabular}{|c|c|c|c|c|c|}
\hline Process & $\begin{array}{c}\text { Modeling } \\
\text { time (second) }\end{array}$ & $\begin{array}{l}\text { Basic check } \\
\text { time (second) }\end{array}$ & $\begin{array}{l}\text { Verification } \\
\text { time (second) }\end{array}$ & $\begin{array}{l}\text { Total time } \\
\text { (second) }\end{array}$ & $\begin{array}{l}\text { Problems } \\
\text { found }\end{array}$ \\
\hline Original Modeling & 175 & 0.40 & 0.81 & 176.21 & 9 \\
\hline Regression 1 & 89 & 0.39 & 0.76 & 90.15 & 0 \\
\hline Total & 264 & 0.79 & 1.57 & 266.36 & 9 \\
\hline \multicolumn{2}{|c|}{ Verification Time/Problems(second) } & 29.60 & \multicolumn{2}{|c|}{ Ratio of Problem Finding } & $100 \%$ \\
\hline
\end{tabular}

Table 19 showed the analysis and inspection time of B1 in group B and the number of problems found.

Table 19. B1 Data record-Target of Safety Production

\begin{tabular}{|c|c|c|c|c|}
\hline Process & $\begin{array}{c}\text { Analysis time } \\
\text { (second) }\end{array}$ & $\begin{array}{c}\text { Verification time } \\
\text { (second) }\end{array}$ & Total time (second) & $\begin{array}{c}\text { Problems } \\
\text { found }\end{array}$ \\
\hline Original Modeling & 321 & 226 & 547 & 5 \\
\hline Regression 1 & 551 & 341 & 892 & 3 \\
\hline Regression 2 & 206 & 268 & 474 & 0 \\
\hline Total & 1078 & 835 & 1913 & 8 \\
\hline Verification Time/Problems(second) & 104.38 & Ratio of Problem Finding & $88.89 \%$ \\
\hline
\end{tabular}

Table 20 shows the analysis and check time of B2 in group B and the number of problems found. In the number of problems found, there were negative numbers which means the B2 had wrongly found problems and corrected them in the end.

Table 20. B2 Data record-Target of Safety Production

\begin{tabular}{|c|c|c|c|c|}
\hline Process & $\begin{array}{l}\text { Analysis time } \\
\text { (second) }\end{array}$ & $\begin{array}{l}\text { Verification time } \\
\quad \text { (second) }\end{array}$ & Total time (second) & $\begin{array}{l}\text { Problems } \\
\text { found }\end{array}$ \\
\hline Original Modeling & 322 & 264 & 586 & 6 \\
\hline Regression 1 & 433 & 350 & 783 & 1 \\
\hline Regression 2 & 264 & 108 & 372 & 2 \\
\hline Regression 3 & 519 & 252 & 771 & -2 \\
\hline Total & 1538 & 974 & 2512 & 7 \\
\hline \multicolumn{2}{|c|}{ Verification Time/Problems(second) } & 139.14 & Ratio of Problem Finding & $77.78 \%$ \\
\hline
\end{tabular}

\subsubsection{Analysis and Summary}

\section{1) Problems and Regression Times}

The problems found in the two experiments of each group were shown in Fig. 16. In Target of Safety Production, that is 9,9,8,7 to A1, A2,B1,B2. It can be seen that A1 and A2 found all 9 
problems, but B1 and B2 only found 8 and 7 problems for each. That means, A1 and A2 found all problems, $\mathrm{B} 1$ and $\mathrm{B} 2$ missed some problems in the original model.

In Major Hazard Monitoring, that is $18,18,14,11$ to A1, A2,B1,B2. It can be seen that A1 and $\mathrm{A} 2$ found all 18 problems, but B1 and B2 only found 14 and 11 problems for each. That means, $\mathrm{A} 1$ and $\mathrm{A} 2$ found all problems, B1 and B2 missed some problems in the original model.

The regression times in the two experiments of each group were shown in Fig. 17. In Target of Safety Production, the regression times is 1 in A1 and A2 that using SOMVT, and 2 times of $\mathrm{B} 1$ and 3 times of $\mathrm{B} 2$ that their analysis is in manual. That is $\mathrm{A} 1$ and $\mathrm{A} 2$ passed the regression all in 1 time dut to the automatical verification and error information provided by SOMVT. And B1 and B2 passed the regression more than one time with 2 and 3 times each due to the limited brain ability and human error.

In Major Hazard Monitoring, the regression times is 1 in A1 and A2 that using SOMVA, and 3 times of $\mathrm{B} 1$ and 5 times of $\mathrm{B} 2$ that their analysis is in manual. That is $\mathrm{A} 1$ and $\mathrm{A} 2$ passed the regression all in 1 time dut to the automatical verification and error information provided by SOMVT. And B1 and B2 passed the regression more than one time with 3 and 5 times each due to the limited brain ability and human error.

Problems Found in Two Experiments

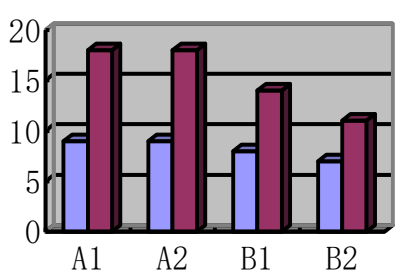

Fig. 16. Problems Found of Each Group

Regression Times in Two Experiments

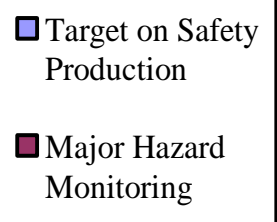

Major Hazar
Monitoring

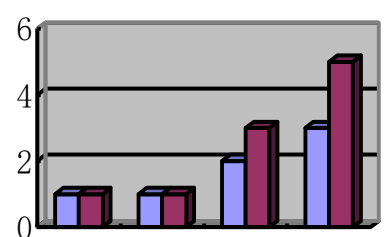

A1 A2 B1 B2

Fig. 17. Regression Times of Each Group

\section{- Summary 1-Problems Found}

It can be seen from the Fig. 16 that Group A found all 9 and 18 problems in two experiments, A1 and A2 got the $100 \%$ to find all problems. That's because all the safety rules has been integrated into the SOMVT based on the axioms in the safety ontology. So the SOMVT can easily check, find and provide the details of all problems to the rules in data base. Though A2 was less skilled, he can also find all problems due to the aid of SOMVT which showed the good effectiveness and easy useability of it.

In Group B, B1 who are more skilled found 8 and 14 problems in two experiments, and got $88.89 \%$ and $77.78 \%$ to find all problems. B2 who are less skilled found 7 and 11 problems in two experiments, and got $77.78 \%$ and $61.11 \%$ to find all problems. That's because the limitation of human brain, it's very hard to find and modify all problems well. With the increasement of problems and complexity in model, there was an obvious decrease in rate of finding all problems only in maunal. The rate of more skilled B1 fell from $88.89 \%$ to $77.78 \%$, and a more rapid decrease of less skilled B2 fell from $77.78 \%$ and $61.11 \%$.

\section{- Summary 2-Number of Regression Times}

It can be seen from the Fig. 17 that the number of regression verification in group A remained at 1 times. In group B, the number of regression verification was 2 times for B 1 and 3 times for B2 in Target on Safety Production, and 3 times for B1 and 5 times for B2 in Major Hazard Monitoring. 
This is mainly because the SOMVT has carried out basic check before verification, and after completing the original modeling and automatic verification, it will give a complete safety analysis report, which clearly summarizes all safety problems and rules broken, which is no need to analysis and modify problems manually for many times. The detailed verification result shown in SOMVT can help analyst very easily know and modify the problems to improve the original model in one time.

At the same time, Group B had more than one regreesion times and increased with the problems and complexity of the model. That's because the limitation of human brain's ability will bring error to the process of analysis and verification which will cause the modification and regressions more and more times.

\section{2) Average Verification Time}

The Average Verification Time equals to the verification time of one problem. The increasement of average verification time of one problem in each group was shown in Fig. 18.

Average Verification Time

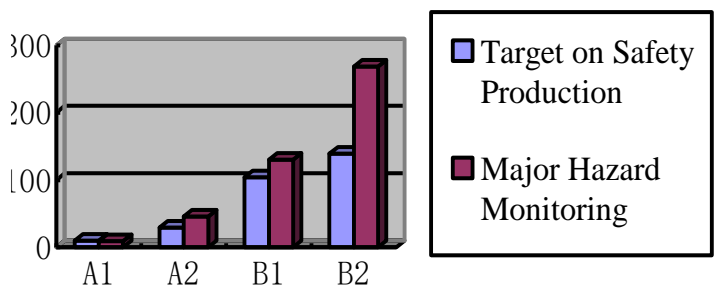

Increasment of Ave-Veri-Time

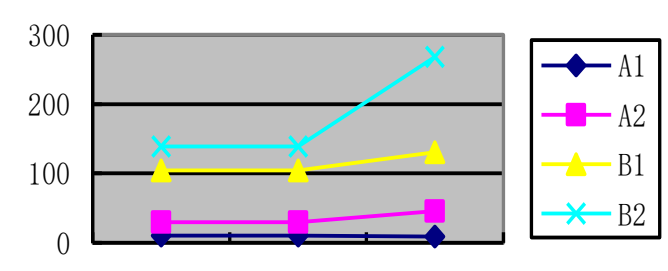

Fig. 18. Average Verification Time of Each Group Fig. 19. Increasment of Average Verification Time

It can be seen from the Fig. 19 that there was an obvious increasing from A1 to B2. Compared with group B2, due to automatic verification and less manual intervention, group A took much less time and increasement, especially A1.

\section{- Summary 3- Average Verification Time}

Based on the analysis of experimental data, it can be seen from Table 10, Table 11, Table 14 and Table 15 that the negative number of problems not found in group A in the verification process. In Table 12, the number of problems found by B1 in group B in the third regression verification during the analysis is -2 . That of $\mathrm{B} 2$ in Table 13 in the second and third regression verification are - 10 and - 2, respectively. In Table 17, the number of problems found by B2 in group B in the third regression verification during the analysis is -2 .

B1 did not use tools but had a longer skilled time, was familiar with the analysis. So the negative time of problems found was only one. B2 did not use the tool and the skilled time was only three months. So in the experiment, B2 had 3 and 5 regression verification times whose errors occurrence was the most frequent and analysis time was the longest.

When the number of problems found in group B is negative, it is mainly due to the introduction of human errors in the manual analysis process. The introduction of human errors will lead to an increase in the time and number of regression verification, and a multiple regression verification which can not guarantee the discovery of all problems.

So with the increasment of problems and complexity of model, Group B in manual obviously had more regression times which led to an obvious more average verification time than Group A using SOMAT. 


\section{- Summary 4- Increasment of Average Verification Time}

The comparison of the increasement of average verification time is shown in Fig. 18. It can be seen from the Fig. 18 that with the increasing number of problems, the average verification time in group A increases slowly. When the complexity increasing, the time to analysis and verification using SOMVT was not much different. At the same time, because the SOMVT can accurately locate and describe the problem, the average verification time of a single problem had no significant change to A1 and A2.

In Group B, the manual process was greatly limited by the individual's ability, and the average verification time increased with the number of problems and complexity of model. Even though B1 is more familiar, due to the lack of verification tools, the verification efficiency was still lower than A2 who used SOMAT only in a short time. B2 who did not use the tool and had a shorter skilled time, so the average verification time of single problem was the longest and the increase was the most rapid.

\section{Conclusion}

The safety management ability of MIS is an important guarantee of enterprise safety production, which should be verified effectively. Based on the "seven steps" method, the safety ontology of shipbuilding and repairing MIS was established, including concepts, associations and axiom set. The concepts, associations and axiom set turned to data table, association table and sql sentence in developed tool-SOMVT. The drag and other operations in SOMVT can automatically add, delete and modify tables in the back. By SOMVT based on the established safety ontology, the safety management ability can be verified by using the corresponding SQL query statements described in SHIQ, so the safety problems of MIS were found. Based on the problems found, the model and database were improved on the safety of MIS. The formal ontology method and SOMVT have the advantages of less verification time, less regression times, higher efficiency, and higher stability. Compared with the manual process of safety verification, SOMVT can analyze the problems much more effectively and stable than manual analysis, which will have a good application prospect in practice.

In future work, we will upgrade the ontology with change and development in ship building and repairing enterprise. Moreover, we will open the interface to build and edition of meta ontology and try to make more automatically in transform from axiom to SQL sentence.

\section{References}

[1] P. Liu and S. Tan, "A Survey of Study on the Competitiveness of China Ship Enterprise," Procedia Engineering, vol. 16, pp. 170-176, 2011. Article (CrossRef Link)

[2] E. Fielt, T. Bohmann, Z. Korthaus, S. Conger, and G. Gable, "Service Management and Engineering in Information Systems Research," Journal of Strategic Information Systems, vol. 22, no. 1, pp. 46-50, 2013. Article (CrossRef Link)

[3] M. Codescu, T. Mossakowski, and O. Kutz, "A Categorical Approach to Networks of Aligned Ontologies,” Journal on Data Semantics, vol. 6, no. 4, pp. 155-197, 2017. Article (CrossRef Link)

[4] S. A. R. Mortazavi and F. Safi-Esfahani, "A checklist based evaluation framework to measure risk of information safety management systems," International Journal of Information Technology, vol. 11, no. 3, pp. 517-534, 2019. Article (CrossRef Link)

[5] A. Gillies, "Improving the quality of information safety management systems with ISO27000," The TQM Journal, vol. 23, no. 4, pp. 367-376, 2011. Article (CrossRef Link) 
[6] J. Webb, A. Ahmad, S. B. Maynard, and G. Shanks, "A situation awareness model for information security risk management," Computers \& Security, vol. 44, pp. 1-15, 2014.

Article (CrossRef Link)

[7] J. Liu, "The Establishment and Implementation of Beijing XX Enterprise Information Security Management System Based on the ISO27001,” Shandong University, 2015. Article (CrossRef Link)

[8] N. Mayer, J. Aubert, E. Grandry, C. Feltus, E. Goettelmann, and R. Wieringa, "An integrated conceptual model for information system safety risk management supported by enterprise architecture management," Software \& Systems Modeling, vol. 18, no. 3, pp. 2285-2312, 2019. Article (CrossRef Link)

[9] L. Zhen, L. Bin, M. Hong, and Y. Yongfeng, "Modeling and verification of software safety requirement based on ontology," Journal of Beijing University of Aeronautics and Astronautics, vol. 38, no. 11, pp. 1445-1449, 2012. Article (CrossRef Link)

[10] R. P. Niranjan and K. Kumar, "An Efficient Software Engineering Ontology Tool for Knowledge Sharing," International Journal of Computer Science Issues (IJCSI), vol. 7, no. 4, pp. 19-27, 2010. Article (CrossRef Link)

[11] O. I. Provotar and O. O. Provotar. "Credibility in Fuzzy Inference Systems," Cybernetics and Systems Analysis,vol. 53, no. 6, pp. 866-875, 2017. Article (CrossRef Link)

[12] T. R. Gruber, "A Translation Approach to Portable Ontology Specification," Knowledge Acquisition, vol. 5, no. 2, pp. 199-220, 1993. Article (CrossRef Link)

[13] N. F. Noy, and D. Mcquinness, "Ontology development 101: A guide to creating your first ontology," Stanford: Stanford Knowledge Systems Laboratory, 2001. Article (CrossRef Link)

[14] L. Jing, "Study on the theory and practice of ontology and ontology-based agricultural document retriecal system-Floricultural ontology modeling," The Chinese Academy of Science, 2004. Article (CrossRef Link)

[15] M. Fernandez-Lopez and A. Gomez-Perez, "METHONTOLOGY: From Ontological Art Towards Ontological Engineering," in Proc. of the AAAI97 Spring Symposium Series on Ontological Engineering, 1997. Article (CrossRef Link)

[16] IDEF, "IDEF5 Ontology Description Capture Overview," [Online]. Avaiable: http://www.idef.com/IDEF5.html

[17] M. Gruninger, M. S. Fox, "Methodology for the Design and Evaluation of Ontologies," in Proc. of Workshop on Basic Ontological Issues in Knowledge Sharing Held in Conjunction with International Joint Conference on Artificial Intelligence ,1995. Article (CrossRef Link)

[18] Borst W. N.. Construction of Engineering Ontologies for Knowledge Sharing and Reuse[D]. Enschede: University of Twente, 1997. Article (CrossRef Link)

[19] ISI Natural language processing research group, "Ontology Creation and Use: SENSUS," [Online]. Available: https://www.isi.edu/natural-language/resources/sensus.html

[20] The KACTUS Booklet version 1.0. Esprit Project 8145. [Online]. Available: http://www.swi.psy.uva.nl/projiects/NewKACTUS/Reports.html

[21] T. Dong, C. Le Duc, M. Lamolle, "Tableau-based revision for expressive description logics with individuals," Web Semantics: Science, Services and Agents on the World Wide Web, vol. 45, pp. 63-79, 2017. Article (CrossRef Link)

[22] Ni Yihua. "The Research of Knowledge Integration Technology based on Ontology for Manufacturing Enterprise," Zhejiang University, 2005. Article (CrossRef Link)

[23] D. Kang, J. Lee, S. Choi, and K. Kim, "An ontology-based Enterprise Architecture," Expert Systems with Applications, vol. 37, pp. 1456-1464, 2010. Article (CrossRef Link)

[24] S. Qinfu, L. Xiulei, L. Xuhong, and S. Liguo, "The study of coal mine safety ontology," Industry and Mine Automation, vol. 44, no. 3, pp. 42-49, 2018. Article (CrossRef Link)

[25] X.Yu, X. Lihong, and Z. Xiaoliang, "Model Building Approach for Nuclear Power Operation Procedure Based on Ontology," Nuclear Power Engineering, vol. 41, no. 5, pp. 142-145, 2020. Article (CrossRef Link) 
[26] R. Motz, E. Rohrer, and P. Severi, "The description logic SHIQ with a flexible meta-modelling hierarchy," Web Semantics: Science, Services and Agents on the World Wide Web, vol. 35, no. 4, pp. 214-234, 2015. Article (CrossRef Link)

[27] K. Solic, H. Ocevcic, and M. Golub, "The information systems' safety level assessment model based on an ontology and evidential reasoning approach," Computers \& Safety, vol. 55, pp. 100-112, 2015. Article (CrossRef Link)

[28] D. Feledi, S. Fenz, and L. Lechner, "Toward web-based information safety knowledge sharing," Information Safety Technical Report, vol. 17, no. 4, pp. 199-209, 2013. Article (CrossRef Link)

[29] G. Mateusz, W. Krzysztof, M. Jakub, and G. Floris, "A bibliometric analysis and systematic review of shipboard Decision Support Systems for accident prevention," Safety Science, pp. 1-22, 2020. Article (CrossRef Link)

[30] I. Arstad and O. A. Engen, "Preventing major accidents and the language of complexity," Policy and Practice in Health and Safety, vol. 16, no. 2, pp. 158-176, 2018.

$\underline{\text { Article (CrossRef Link) }}$ 


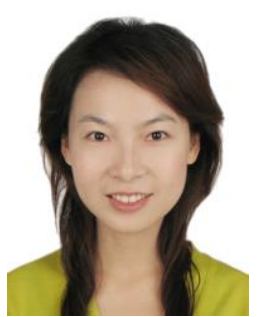

YuMei Wu got the doctor degree of system egineering from School of Reliability and Systems Engineering in Beihang University and is a lecturer now. Her interests include software reliability and testing, reliability and system engineering.

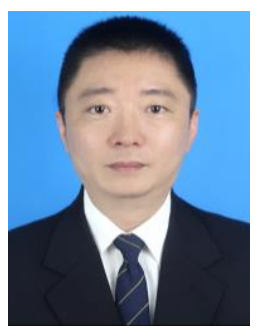

Zhen Li got the doctor degree of system egineering from School of Reliability and Systems Engineering in Beihang University and now is an associtated professor of School of Electronics and Information in Jiangsu University of Science and Technology. His interests include software reliability and testing, reliability and system engineering.

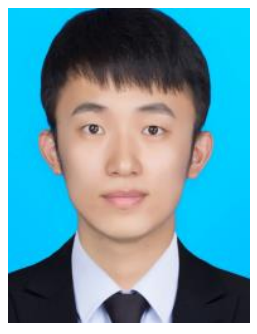

LanJie Zhao got the master degree of electronics and communication from School of Electronics and Information in Jiangsu University of Science and Technology and now is an engineer. His interests include reliability and system engineering, information security.

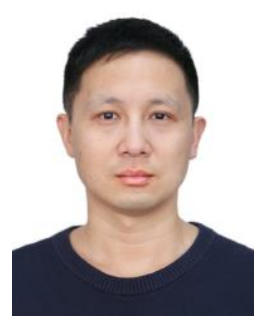

ZhengWei Yu got the doctor degree of system egineering from School of Reliability and Systems Engineering in Beihang University and is a lecture now. His interests include software reliability and testing, reliability and system engineering.

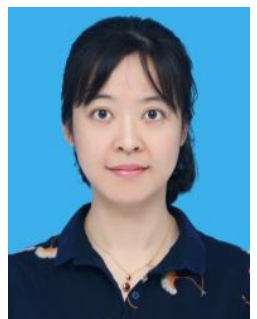

Hong Miao got the doctor degree of control egineering from School of Automation in NanJing University of Science and Technology and now is an associtated professor School of Economics and Management in Jiangsu University of Science and Technology. Her interests include modeling and analysis of MIS, qulity of information system and software. 